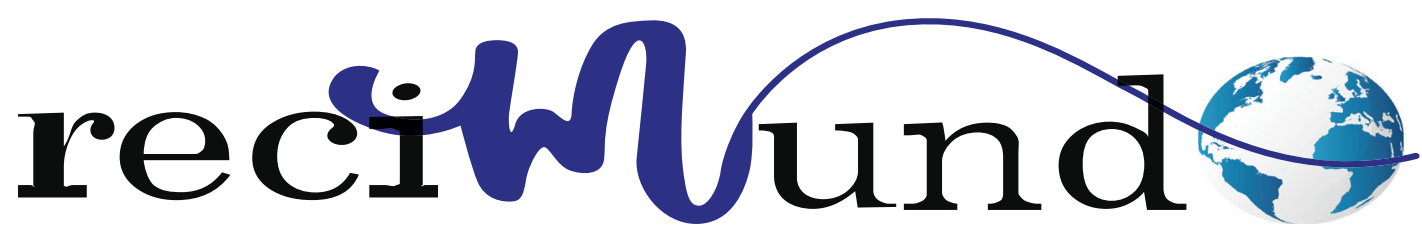

Revista Científica Mundo de la Investigación y el Conocimiento

DOI: 10.26820/recimundo/4.(4).noviembre.2020.200-206

URL: http://recimundo.com/index.php/es/article/view/939

EDITORIAL: Saberes del Conocimiento

REVISTA: RECIMUNDO

ISSN: 2588-073X

TIPO DE INVESTIGACIÓN: Reporte de caso

Código UNESCO: 32 Ciencias Médicas

PAGINAS: $200-206$

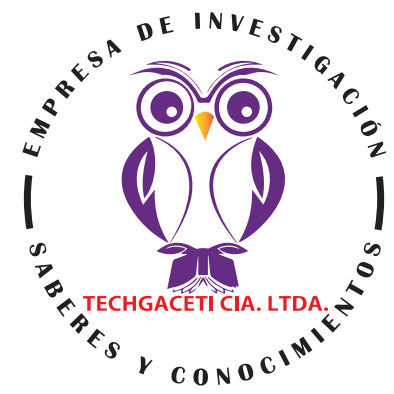

\title{
Neumonitis asociada al uso de metotrexate
}

Pneumonitis associated with the use of methotrexate

Pneumonite associada ao uso de metotrexato

Wilson Pita M'; Priscylla Quezada J2; María José Pino P3; Diana Uchuari M

RECIBIDO: 30/08/2020 ACEPTADO: 26/09/2020 PUBLICADO: 10/11/2020

1. Médico Residente de Medicina Intensiva; Hospital Clínica San Francisco; Guayaquil, Ecuador; wpita@uees.edu.ec; https://orcid.org/0000-0003-1077-8679

2. Médico Residente de Medicina Intensiva; Hospital Clínica San Francisco; Guayaquil, Ecuador; pquezadaj@uees.edu.ec; (iD) https://orcid.org/0000-0002-4171-8487

3. Médico Residente de Medicina Interna; Hospital Luis Vernaza; Facultad de Postgrado de la Universidad Espíritu Santo; Guayaquil, Ecuador; mpinopin@uees.edu.ec; iD https://orcid.org/0000-0002-1154-0884

4. Médico Residente de Medicina Intensiva; Hospital Oncológico SOLCA; Guayaquil, Ecuador; duchuari@uees.edu.ec; https://orcid.org/0000-0001-5465-0285

\section{CORRESPONDENCIA}

Wilson Pita M.

wpita@uees.edu.ec

Guayaquil, Ecuador

() RECIMUNDO; Editorial Saberes del Conocimiento, 2020 


\section{RESUMEN}

La neumonitis por metotrexate es una complicación aguda y grave que se caracteriza por la instauración de tos seca, disnea y fiebre, con aparición de un patrón radiológico de infiltrado intersticial que obliga a la retirada del fármaco. Su patogenia se atribuye a un mecanismo de hipersensibilidad y se recomienda no reintroducir el metotrexato tras su resolución. Los factores de riesgo reconocidos son la edad avanzada, la diabetes mellitus, la hipoalbuminemia y las manifestaciones extra articulares de la artritis reumatoide, especialmente la pulmonar. El tratamiento con glucocorticoides a dosis altas y las medidas de soporte respiratorio favorecen la resolución clínica completa, aunque la mortalidad alcanza el 10-18\% de las series. Presentamos el caso de un paciente masculino de 57 años que tiene antecedentes de artritis reumatoidea tratado con metotrexato desde hace 8 meses, que presento un cuadro clínico de 5 días de evolución caracterizado por disnea de medianos esfuerzos, tos seca, cuyos síntomas progresaron hasta presentar signos de insuficiencia respiratoria aguda tipo hipoxemica. Fue ingresado con necesidad de ventilación mecánica. Se realizaron exámenes de imágenes que mostraron un patrón intersticial bilateral diseminado. Que posterior a descarte de patologías más frecuentes, se asoció el cuadro clínico a neumonitis por metotrexato. Con tal diagnóstico se procedió a la administración de corticoides con evolución favorable.

Palabras clave: Neumonitis, Metrotexate, Toxicidad, Corticoides, Pulmonar

\section{ABSTRACT}

Methotrexate pneumonitis is an acute and serious complication characterized by the onset of a dry cough, dyspnea, and fever, with the appearance of a radiological pattern of interstitial infiltrate that requires drug withdrawal. Its pathogenesis is attributed to a hypersensitivity mechanism and it is recommended not to reintroduce methotrexate after its resolution. Recognized risk factors are advanced age, diabetes mellitus, hypoalbuminemia, and the extra-articular manifestations of rheumatoid arthritis, especially pulmonary arthritis. Treatment with high-dose glucocorticoids and respiratory support measures favor complete clinical resolution, although mortality reaches $10-18 \%$ of series. We present the case of a 57 -yearold male patient who has a history of rheumatoid arthritis treated with methotrexate for 8 months, who presented a clinical picture of 5 days of evolution characterized by dyspnea on medium efforts, dry cough, whose symptoms progressed until presenting signs of hypoxemic type acute respiratory failure. He was admitted in need of mechanical ventilation. Imaging examinations were performed that showed a disseminated bilateral interstitial pattern. That after ruling out more frequent pathologies, the clinical picture was associated with methotrexate pneumonitis. With such a diagnosis, corticosteroids were administered with a favorable outcome.

Keywords: Pneumonitis, Methotrexate, Toxicity, Corticosteroids, Pulmonary.

\section{RESUMO}

A pneumonite por metotrexato é uma complicação aguda e grave caracterizada pelo aparecimento de tosse seca, dispneia e febre, com o aparecimento de um padrão radiológico de infiltrado intersticial que requer a suspensão do medicamento. Sua patogênese é atribuída a um mecanismo de hipersensibilidade e recomenda-se não reintroduzir o metotrexato após sua resolução. Os fatores de risco reconhecidos são idade avançada, diabetes mellitus, hipoalbuminemia e as manifestações extra-articulares da artrite reumatoide, especialmente artrite pulmonar. $\mathrm{O}$ tratamento com glicocorticoides em altas doses e medidas de suporte respiratório favorecem a resolução clínica completa, embora a mortalidade alcance 10-18\% das séries. Apresentamos o caso de um paciente do sexo masculino, 57 anos, com história de artrite reumatoide tratada com metotrexato há 8 meses, que apresentava quadro clínico de 5 dias de evolução caracterizado por dispneia aos médios esforços, tosse seca, cujos sintomas progrediram até apresentar sinais de insuficiência respiratória aguda do tipo hipoxêmico. Ele foi internado com necessidade de ventilação mecânica. Foram realizados exames de imagem que mostraram um padrão intersticial bilateral disseminado. Que após afastar patologias mais frequentes, o quadro clínico foi associado a pneumonite por metotrexato. Com esse diagnóstico, os corticosteroides foram administrados com um resultado favorável.

Palavras-chave: Pneumonite, Metotrexato, Toxicidade, Corticosteróides, Pulmonar. 


\section{Introducción}

Existen un gran número de fármacos que son capaces de producir patología del sistema respiratorio, fundamentalmente del parénquima pulmonar, pero también de la pleura y del mediastino. Con la aparición de nuevos fármacos, la lista de sustancias potencialmente lesivas para el pulmón va en aumento. Durante la anamnesis sobre cualquier enfermedad pulmonar se debe preguntar e insistir en los fármacos administrados tanto de forma reciente como en el pasado, dado que la reacción adversa en el pulmón puede manifestarse meses o incluso años después de la exposición a la droga causante (1).

El metotrexate es un análogo del ácido fólico que impide la proliferación celular inhibiendo de forma competitiva la enzima dihidrofolato reductasa; bloquea así la conversión de dihidrofolato a tetrahidrofolato. Este compuesto tiene acción antiinflamatoria e inmunomoduladora y es empleado como tratamiento crónico de enfermedades inflamatorias, artritis reumatoide y psoriasis. En la literatura se observa que más del 50 \% de los pacientes tratados con metotrexato presentarán al menos una reacción adversa; las más frecuentes son cutáneas, gastrointestinales o del sistema nervioso central. No suelen ser graves, pero hasta el 30 $\%$ de los pacientes se ven obligados a detener el tratamiento por la toxicidad. Los efectos secundarios también pueden ser graves y potencialmente mortales; destacan la toxicidad pulmonar, la hepática y las alteraciones hematológicas. Entre las primeras se encuentra la neumonitis por metotrexato (2). El mecanismo de acción del MTX es complejo y no se conoce con exactitud, aunque se postulan 4 posibles mecanismos: a) inhibición de la síntesis de purinas y pirimidinas; b) disminución de la acumulación de agentes tóxicos como las poliaminas; c) reducción de la proliferación de células del sistema inmunológico, y d) aumento de los valores extracelulares de adenosina (puri- na). Es de este último mecanismo del que más evidencias se dispone (3).

Diversos efectos adversos son atribuidos a su uso. Pueden aparecer síntomas generales, como fatiga, mareos, fiebre y pérdida de peso. Los síntomas gastrointestinales reportados son: anorexia, dolor abdominal, náusea, diarreas, estomatitis o mucositis. En piel se puede encontrar rash, urticaria o alopecia. Hematológicamente destacan macrocitosis, leucopenia y pancitopenia. La toxicidad pulmonar puede ir desde una enfermedad pulmonar inmunoalérgica, bronquitis o neumonía, reportándose algunos casos de infección por gérmenes oportunistas entre ellos el Pneumocysti Carinii (4). En la década de los ochenta del pasado siglo se afianzaron los conocimientos de la farmacocinética y seguridad en el manejo del fármaco. Las directrices para la utilización correcta del metotrexato y la prevención de la toxicidad hepática están bien establecidas desde hace tiempo. Por el contrario, aunque en la década de los noventa del pasado siglo proliferaron las comunicaciones que hacían referencia a la toxicidad pulmonar, no hay consenso en las medidas a realizar en la prevención de la neumonitis (5).

\section{Descripción del caso clínico}

Paciente masculino de 57 años, de ocupación abogado con antecedentes de obesidad mórbida, hipertensión arterial con abandono del tratamiento hace 1 año, rinitis, estreñimiento, litiasis renal, niega hábitos de alcohol y de cigarrillo, con artritis reumatoidea tratado con metrotexate $3,5 \mathrm{mg}$ cada semana, desde hace 8 meses. Presenta un cuadro clínico de 3 días de evolución previó a su ingreso caracterizado por disnea progresiva, tos seca, palidez. El cuadro clínico se agrava llevando al paciente a una insuficiencia respiratoria grave. Es valorado en un centro asistencial donde lo catalogan como neumonía grave de la comunidad y es internado en el área de cuidados intensi- 
vos donde el cuadro clínico progresa hasta llegar a necesitar protección de la vía aérea mediante intubación endotraqueal y conectarlo a ventilación mecánica.

A su ingreso paciente bajo sedoanalgesia, al examen físico llama la atención estertores crepitantes bilaterales, con disminución del murmullo vesicular a nivel bibasal. Se realizan exámenes de laboratorio donde nos llama la atención los marcadores infecciosos discretamente elevados con valores de Procalcitonina 1.79ug/ml, interleucina 6: pg/ $\mathrm{ml}$, PCR: $133 \mathrm{mg} / \mathrm{ml}$ y exámenes virales de influenza $A$, B con resultados negativos Por otra parte, destaca disfunción renal aguda con urea: $166 \mathrm{mg} / \mathrm{dl}$, creatinina: $4.31 \mathrm{mg} / \mathrm{dl}$; se inicia esquema antibiótico empírico con meropenem/Colistin/fluconazol pues el paciente había acudido a otra casa de salud y sospechábamos de gérmenes multiresis- tentes que haya adquirido en la otra unidad donde fue atendido. Al no apreciar mejoría con 3 días de tratamiento, se reevalúan las imágenes tomográficas de pulmón donde prevalecen características de infiltrado intersticial (fig. 1). Asociado a esto presenta cultivos de sangre negativos. Se suspende tratamiento antimicrobiano y se decide iniciar tratamiento con corticoides (metilprednisolona) con dosis de $1 \mathrm{mg} / \mathrm{kg}$ pues presentaba alta sospecha de neumonitis por metrotexate basados en los criterios de Alarcón (Tabla 1).

Es así como a las 24 horas de tratamiento se aprecia mejoría clínico y radiográfico y descenso de marcadores inflamatorios e infecciosos. 3 días posteriores al inicio de tratamiento con corticoides el paciente es extubado.

Tabla 1: Sospecha de neumonitis por Metrotexate basado en los criterios de Alarcón

\begin{tabular}{|c|}
\hline $\begin{array}{c}\text { CRITERIOS MAYORES } \\
\text { 1. Neumonitis por hipersensibilidad por histopatología, sin evidencia de organismos } \\
\text { patógenos }\end{array}$ \\
\hline 2. Infiltrados radiológicos intersticiales o alveolares \\
\hline 3. Hemocultivos y cultivo de esputo negativos \\
\hline CRITERIOS MENORES \\
\hline 1. Disnea de menos de 8 semanas de evolución \\
\hline 2. Tos seca \\
\hline 3. Saturación basal de O2 < 90\% \\
\hline 4. DLCO $<70 \%$ del teórico \\
\hline 5. Leucocitos < 15.000/mm3 \\
\hline CRITERIOS MENORES \\
\hline 1. Disnea de menos de 8 semanas de evolución \\
\hline 2. Tos seca \\
\hline 3. Saturación basal de O2 < 90\% \\
\hline 4. DLCO $<70 \%$ del teórico \\
\hline 5. Leucocitos < 15.000/mm3 \\
\hline
\end{tabular}

Fuente: (6). 
Figura 1: Tomografía de pulmón con patrón de infiltrado intersticial

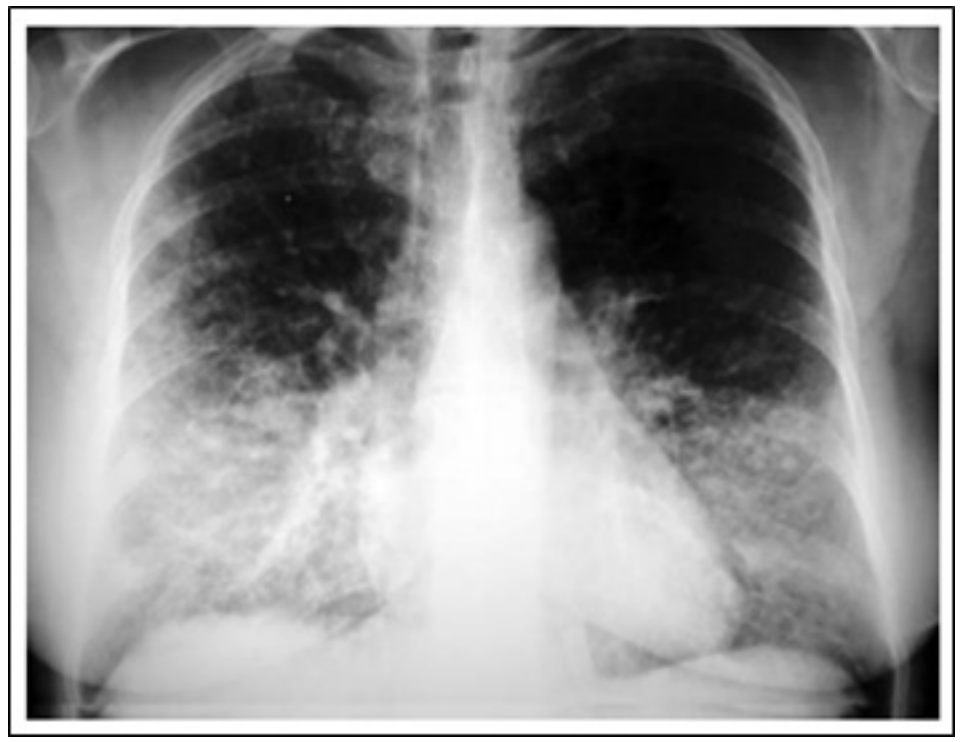

Fuente: (2).

\section{Discusión}

Las alteraciones pulmonares observadas en pacientes que reciben tratamiento con metotrexate pueden ser infecciosas, inflamatorias y posiblemente neoplásicas aunque este último mecanismo de producción es desconocido. Se ha sugerido que el tratamiento mantenido con metotrexate puede favorecer la proliferación de linfomas aunque esto no está totalmente demostrado (5). Entre las causas infecciosas, la inmunosupresión que provoca, aumenta el riesgo de infecciones oportunistas, siendo la más frecuente la producida por Pneumocystis jiroveci (2).

La forma de presentación puede ser aguda, subaguda o crónica. De todas ellas la forma más frecuente es la subaguda en la que la toxicidad se desarrolla en el primer año de tratamiento. Cursa con disnea, tos no productiva, fiebre, cianosis y evolución a fibrosis en el $10 \%$ de los casos. Un $20 \%$ de los pacientes presentan manifestaciones cutáneas y hasta el 50\% eosinofilia periférica. La forma aguda aparece hasta en el $5 \%$ de pacientes tratados por artritis reumatoide y cursa con síntomas inespecíficos, tanto res- piratorios como sistémicos, que progresan durante semanas, pudiendo evolucionar a un fallo respiratorio rápidamente (2).

No existe ninguna prueba diagnóstica definitiva por lo que el diagnóstico requiere un alto índice de sospecha y apoyarse en la clínica, radiología y resultados obtenidos tras la retirada del fármaco. Ocasionalmente puede ser de utilidad los datos obtenidos del lavado broncoalveolar (LBA) y biopsia pulmonar. La alteración radiológica más característica es la afectación intersticial difusa. En algunos pacientes este patrón evoluciona a un infiltrado alveolar parcheado y lesiones nodulares. En una minoría de casos pueden observarse otras alteraciones radiológicas (adenopatías hiliares, atelectasias, derrame pleural). Es excepcional observar una radiografía tórax normal. La tomografía de alta resolución (TACAR) es más sensible que la radiología simple para detectar la afectación intersticial. La extensión de las lesiones en la TACAR se correlaciona con la disminución de los volúmenes pulmonares en las pruebas de función respiratoria (PFR). Un patrón restrictivo con disminución de la capacidad de difusión del CO (DLCO) es el hallazgo más frecuente observado en 
las PFR de estos pacientes (2).

Tanto los resultados obtenidos en el LBA como en la biopsia pulmonar son inespecíficos y pueden estar presentes en otros procesos de naturaleza inflamatoria. Los hallazgos observados en la biopsia pulmonar son alveolitis con hiperplasia de células epiteliales, infiltrado de eosinófilos, pequeños granulomas y fibrosis extensa con áreas en panal de abeja de predominio en bases. Ninguna de estas dos exploraciones complementarias es obligatoria para establecer el diagnóstico de neumonitis por metotrexate. Searles y McKendry propusieron unos criterios para el diagnóstico de la toxicidad pulmonar por metotrexate cuya utilidad clínica debe individualizarse (2).

Respecto al tratamiento es imprescindible descartar causas infecciosas. Así ante la sospecha de enfermedad infecciosa está indicada la terapia antimicrobiana empírica una vez extraídas muestras biológicas para cultivo. El primer paso en el tratamiento ante la sospecha de neumonitis por metotrexate consiste en la retirada de dicho fármaco tan pronto como sea posible. En la mayoría de casos, esto provoca una mejoría clínica en los siguientes días, seguida de una mejoría radiológica a lo largo de semanas. El tratamiento con corticoides no está avalado por estudios que apoyen su uso, si bien se han descrito casos en que se han empleado con éxito. Su uso podría estar justificado en caso de afectación clínica muy importante o en caso de persistir alteraciones clínicas o radiológicas a pesar de retirar el metotrexate. Se recomienda comenzar con metilprednisolona a dosis de $1 \mathrm{mg} / \mathrm{kg}$ peso/día. En aquellos casos con mala respuesta se ha descrito mejoría de la función pulmonar tras tratamiento con ciclofosfamida. En la mayoría de casos la recuperación es completa, si bien un porcentaje variable de pacientes pude mostrar secuelas radiológicas o en las pruebas de función respiratoria. La administración de ácido fólico, utilizada de forma concomitante junto al metotrexate para atenuar o evitar los síntomas gastrointestinales, las alteraciones hematológicas o de las pruebas de función hepática, no ha demostrado su efectividad en la prevención de la toxicidad pulmonar, si bien se ha objetivado cierta eficacia del ácido folínico (2).

\section{Conclusión}

El presente caso de Neumonitis por metotrexato reviste de importancia ya que su entidad es poco frecuente, cuyo diagnóstico se basa en la sospecha clínica y por exclusión. Su fisiopatología es incierta: sugiere una base idiosincrásica. Se ha postulado un algoritmo diagnóstico sin pruebas específicas, aunque se ha observado una posible relación con las características del lavado broncoalveolar que pueden correlacionarse con un peor pronóstico. Son necesarios futuros estudios para conocer mejor esta entidad.

\section{Bibliografía}

1. Carrera LG, Sánchez CP, Walter RÁS. ENFERMEDADES PULMONARES INTERSTICIALES INDUCIDAS POR FÁRMACOS Y RADIOTERAPIA.

2. Sáenz Abad D, Ruiz-Ruiz FJ, Monón Ballarín S, Duarte J, Marquina Barcos A. Neumonitis secundaria a metotrexate. In Anales de medicina interna. 2008; 25(1): p. 27-30.

3. Moya P, Corominas H, Salazar J, Baiget M. Farmacogenética del metotrexato. Reumatol. clín. (Barc.). 2016; 11(1): p. 8-15.

4. García EE, Pérez TC, López CB, Martín TR. Efectos adversos tras el uso parenteral del Metotrexate. Revista Cubana de Reumatología: RCuR. 2000; 2(2): p. 77-85.

5. Igualada Quintanilla J, Romero Candel G, Tejada Cifuentes F. Metotrexato: toxicidad pulmonar, hepática y hematológica. Revista Clínica de Medicina de Familia. 2016; 9(3): p. 159-166.

6. Alarcon GS, Kremer JM, Macaluso M, Weinblatt ME, Cannon GW, Palmer WR. Risk factors for methotrexate-induced lung injury in patients with rheumatoid arthritis: A multicenter, case-control study. Ann Intern Med. 1997; 127: p. 356-64.

7. Mateo-Soria L. Toxicidad pulmonar inducida por metotrexato. Seminarios de La Fundación Española de Reumatología. 2005; 6(4): p. 176-182. 


\section{(c) $)$ (i) $(2)$ \\ CREATIVE COMMONS RECONOCIMIENTO-NOCO- MERCIAL-COMPARTIRIGUAL 4.0.}

\section{CITAR ESTE ARTICULO:}

Pita M, W., Quezada J, P., Pino P, M. J., \& Uchuari M, D. (2020). Neumonitis asociada al uso de metotrexate. RECIMUNDO, 4(4), 200-206. https://doi.org/10.26820/recimundo/4.(4).noviembre.2020.200-206 